\section{Using Cucurbita Rootstocks to Reduce Fusarium Wilt Incidence and Increase Fruit Yield and Carotenoid Content in Oriental Melons}

\author{
Xianzhi Zhou, Yufen $\mathrm{Wu}^{1}$, Sheng Chen, Yang Chen, \\ and Weiguang Zhang ${ }^{1}$ \\ Agricultural Bio-Resources Research Institute, Fujian Academy of Agricultural \\ Sciences, Wusi Road 247, Fuzhou 350003, China
}

Xintao Sun

Xiamen Ento-exit Inspection and Quarantine Bureau, Xiamen 361012, China

\author{
Yijie Zhao \\ Fuzhou Institute of Agricultural Sciences, Fuzhou 350018, China
}

Additional index words. cucurbit, $\beta$-carotene, $\zeta$-carotene, Fusarium oxysporum f. sp. melonis, lutein, phytofluene

\begin{abstract}
Oriental melon (Cucumis melo var. makuwa Makino) is a fruit with distinctive characteristics that is grown in Fuzhou, China. Fusarium wilt disease management remains a major challenge in the production of this fruit. Here, we performed seven field trials at four locations in Fuzhou, Fujian Province, China, to evaluate the control of fusarium wilt and yield of Oriental melons grafted on two Cucurbita rootstocks [Shengyan Tianzhen (SYTZ) and Nanzhen No. 1 (NZ1)]. During the growing seasons of 2008 to 2011, Oriental melons grafted on SYTZ and NZ1 exhibited dramatically reduced incidences of fusarium wilt disease and increased yields compared with nongrafted Oriental melons. Disease was only recorded in Trial 3 at Hongwei (2009), where plants grafted on SYTZ and NZ1 exhibited $1.05 \%$ and $1.1 \%$ infection, respectively. In the other six field trials, wilting was not observed at all. In comparison, the incidence of the disease in nongrafted Oriental melons ranged from $45.0 \%$ to $100.0 \%$. The use of Cucurbita rootstocks improved the qualitative and quantitative carotenoid profiles, increasing lutein levels $\left(12.7\right.$ and $10.8 \mu \mathrm{g} \cdot \mathrm{g}^{-1}$ of fresh weight, respectively) and $\zeta$-carotene and phytofluene amounts in fruit samples from SYTZ- and NZ1-grafted plants. In particular, the Liyu/NZ1 combination significantly increased $\beta$-carotene content $\approx 4$-fold compared with nongrafted samples. In conclusion, $C$ ucurbita rootstocks provided acceptable protection of Oriental melon cv. Liyu against fusarium wilt and improved the productivity and quality of fruits.
\end{abstract}

Oriental melon (Cucumis melo var. makuwa Makino) is an important germplasm resource of melon in China and is cultivated in Fuzhou (Fujian Province, China) for its delicious sweetness, high nutrient quality, and flavor. Fusarium wilt of Oriental melons, which is caused by Fusarium oxysporum $\mathrm{f}$. sp. melonis (FOM), is a serious challenge in Oriental melon production (Qi et al., 2006a; Wu et al., 2006; Wu and Zhao, 2007; Zhao et al., 2010, 2012a, $2012 \mathrm{~b}$ ). Wilting symptoms and plant death caused by FOM may be devastating with up to $100 \%$ losses (Zhao et al., 2012a). Several strategies have been recommended to control this disease, including the use of resistant

Received for publication 10 June 2014. Accepted for publication 3 Sept. 2014.

This research was supported by the scientific special expenditure for non-profit public industry of China (200903049-08).

${ }^{1}$ To whom reprint requests should be addressed; e-mail yifenwu1965@163.com (Y.W.); weiguang zhang126@126.com (W.Z.).
2010). Moreover, quality parameters such as acidity, soluble solids contents (SSC), sugar, titratable acid, vitamin C, flavor, aroma, color, carotenoid content, amino acid content, and texture have been shown to be affected by grafting and the type of rootstock used. However, it is still unclear whether these effects are advantageous or deleterious (Davis et al., 2008; Huang et al., 2012; Rouphael et al., 2008; Wu et al., 2006). The choice of rootstock is mainly based on the resistance to pathogens and on the effects of the rootstock on plant productivity and external quality attributes of the fruits, e.g., size, shape, and color. However, important internal quality attributes such as health-promoting compounds should also be considered to achieve the satisfaction of consumers who are becoming more and more interested in the nutritional qualities of vegetable products (Rouphael et al., 2008).

Carotenoids are recognized as playing an important role in the prevention of human diseases and maintaining good health. In epidemiological studies, an inverse relationship has been demonstrated between carotenoid intake or serum carotenoid levels and the risk of various chronic diseases (AlvesRodrigues and Shao, 2004; Chuwers et al., 1997; Gaziano et al., 1995; Johnson, 2002; Rao and Rao, 2007; Slattery et al., 2000). In addition, women with higher circulating levels of $\alpha$-carotene, $\beta$-carotene, lutein plus zeaxanthin, lycopene, and total carotenoids may be at reduced risk of breast cancer (Eliassen et al., 2012). Carotenoids are among the most abundant naturally occurring pigments in plants, and plant foods and melon fruits are an excellent source of carotenoids. Primarily $\beta$ carotene, but also $\alpha$ - and $\zeta$-carotene, lutein, $\beta$-cryptoxanthin, phytoene (Yano et al., 2005), violaxanthin (Laur and Tian, 2011), neoxantin, and zeaxanthin (Khachik et al., 1991), have been detected. Nevertheless, published data on the qualitative and quantitative carotenoid contents of melon show substantial variations among different melon varieties as well as among melons grown under different field conditions, harvested at different times, and harvested from different locations. Moreover, Laur and Tian (2011) reported that cantaloupe melons accumulate up to 60 -fold more $\beta$-carotene than honeydew melons, and Lester and Eischen (1996) found that $\beta$-carotene contents of muskmelon varied by size class, soil type, and cultivar from 5.3 to $33.8 \mu \mathrm{g} \cdot \mathrm{g}^{-1}$ fresh weight. Li (2013) observed that the carotenoid content of Oriental melon decreased with an increase in ploidy. Additionally, Condurso et al. (2012) found that pumpkin hybrid rootstocks could improve the qualitative and quantitative carotenoid profiles of melon cv. Proteo (Cucumis melo L. var. reticulatus). Thus, the characteristics of the cultivars, climate, conditions, and grafting for growing vegetable crops and different ploidy levels for vegetable crops may produce fruits whose carotenoid profiles can differ considerably.

In a previous study by $\mathrm{Wu}$ et al. (2006), the results of grafting Liyu Oriental melon 
C. melo L. var makuwa Makino onto Cucurbita rootstocks SYTZ and NZ1 in FOM-infested soils in Lianjiang, Fuzhou, China, indicated that grafted Oriental melons performed better than nongrafted Oriental melons with respect to growth development, yield, and fusarium wilt control. The plants grafted onto SYTZ and NZ1 had $91.7 \%$ and $95.4 \%$ survival rates, respectively, significantly higher than those of the nongrafted melons and five other combinations, which also exhibited symptoms of fusarium wilt. Interestingly, wilting was not observed in Oriental melons grafted onto SYTZ and NZ1 rootstocks. Obvious differences were not observed in the sensory quality, firmness, or color of Oriental melons grafted onto SYTZ and NZ1 rootstocks compared with nongrafted Liyu Oriental melons. However, the SSC and soluble sugar content of nongrafted Liyu Oriental melons were higher compared with grafted Liyu Oriental melons, whereas grafted Liyu Oriental melons had higher vitamin $\mathrm{C}$ and protein content.

In the Fujian Province of China, the Danyang district, Baisha district, Hongwei district, and Geling district of Fuzhou city are the four main areas in which Oriental melons are grown, and fusarium wilt is one of the major factors limiting the production of Oriental melons in these areas. The race 2 strain of fusarium wilt is wildly distributed in Fuzhou. In contrast, strains of race 0 and race $1,2 \mathrm{y}$ have been found in samples from Danyang and Hongwei, suggesting a restricted distribution of these two races in Fuzhou. Race 1 was not detected in our sample and has not been reported from China (data not shown).

In this study, we aimed to determine whether Cucurbita rootstocks SYTZ and NZ1 could improve the resistance against fusarium wilt and increase yield in different locations or during different seasons in Fuzhou. We also examined the carotenoid contents in Oriental melon fruits.

\section{Materials and Methods}

Plant materials. Liyu Oriental melon $C$. melo L. var. makuwa Makino (KNOWN-YOU Seed Co., Ltd., Taiwan, China) was used as the scion. SYTZ $(C$. maxima $\times C$. moschata $)$ (Xi'an SHENGYAN Seed Co., Ltd., Xi'an, China) and NZ1 (C. moschata $\times$ C. moschata) (Agricultural Bio-Resources Research Institute, Fujian Academy of Agricultural Sciences, Fuzhou, China) were used as the rootstocks. Liyu Oriental melon is a fusariumsusceptible melon that is susceptible to all FOM races, whereas SYTZ and NZ1 are resistant to all four races of FOM.

Grafting method. The tongue approach was used for grafting the scion onto to the rootstocks according to the procedure described by Wu et al. (2006). Seeds of Liyu Oriental melon, NZ1, and SYTZ were sown in seedling trays filled with a mixture of one perlite:two peat:one mushroom compost dregs (v/v). Liyu Oriental melon seeds were sown $5 \mathrm{~d}$ earlier than rootstock seeds. The plants were grown in an environmentally controlled greenhouse at 25 and $20^{\circ} \mathrm{C}$ during the day and night (12 h:12 h), respectively, and were grafted at the two-leaf stage. The true leaves and growing point of the rootstocks were removed with a razor blade; a notch was cut in the rootstock $(0.5$ to $1.0 \mathrm{~cm}$ below the cotyledonary node) and in the scion ( 2.0 to $2.5 \mathrm{~cm}$ below the cotyledonary node). The plants were then clipped together at their notches and allowed to heal for $10 \mathrm{~d}$ before severing the roots of the scion and the shoots of the rootstock.

Field study. The performance of Oriental melons grafted onto Cucurbita rootstocks was evaluated in seven field experiments at four different locations in Fuzhou, Fujian Province, China. Furthermore, all field experiments were conducted in naturally fusarium-infested soils. All field trials included the three grafted combinations: Liyu Oriental melons grafted onto SYTZ rootstock (Liyu/SYTZ) and NZ1 rootstock (Liyu/NZ1), whereas nongrafted Liyu Oriental melons (nongrafted Liyu) were used as controls. A randomized block experimental design was used. Each plot was $12 \mathrm{~m}$ in length and $4 \mathrm{~m}$ in width, and 80 grafted or nongrafted Liyu Oriental melons seedlings were transplanted in each plot. The field was covered with plastic film. Except for the application of fungicides, standard agronomic practices were conducted to cultivate the crop. In all field experiments, preplant broadcast $12 \mathrm{~N}-15 \mathrm{P}-18 \mathrm{~K}$ fertilizer was applied at a dose of $300 \mathrm{~kg} \cdot \mathrm{ha}^{-1}$ to all plots. Additional nitrogen $(\mathrm{N})$ at $80 \mathrm{~kg} \cdot \mathrm{ha}^{-1}$, potassium $(\mathrm{K})$ at $110 \mathrm{~kg} \cdot \mathrm{ha}^{-1}$, and calcium at $46 \mathrm{~kg} \cdot \mathrm{ha}^{-1}$ were applied as potassium nitrate (13:0:44), calcium nitrate (15.5:0:0: $19)$, and ammonium nitrate (34:0:0) through a drip irrigation system in four equal proportions at 10 -d intervals starting 2 weeks after transplanting.

Meteorological data (rainfall and temperature) in the field trial sites were obtained from Fuzhou Meteorology Bureau. Trial 1 was conducted from 18 Apr. to 22 Apr. 2008 in Fujian Province in the Danyang district of Fuzhou City (lat. $26.21^{\circ} \mathrm{N}$, long. $119.27^{\circ} \mathrm{E}$ ) with six replications of each treatment. Oriental melons were harvested five times from 5 July to 31 July 2008. During Trial 1, the temperature ranged from 15.5 to $36.7^{\circ} \mathrm{C}$ with a cumulative precipitation of $415.8 \mathrm{~mm}$. Trials 2 and 3 were conducted from 9 July to 12 July 2008 and 7 Feb. to 13 Feb. 2009 , respectively, in Fujian Province at the Hongwei district of Fuzhou City (lat. $26.17^{\circ} \mathrm{N}$, long. $\left.118.99^{\circ} \mathrm{E}\right)$. There were nine and 20 replications of each treatment in Trials 2 and 3 , respectively. Oriental melons were harvested seven times from 15 Sept. to 25 Sept. 2008 in Trial 2 and nine times from 23 Apr. to 10 May 2009 in Trial 3. During the periods for Trials 2 and 3, the temperature ranged from 25.3 to $38.5^{\circ} \mathrm{C}$ and 26.3 to $38.8^{\circ} \mathrm{C}$ with cumulative precipitation levels of 485.8 and $505.4 \mathrm{~mm}$, respectively. Trial 4 was conducted from 2 Mar. to 6 Mar. 2010 in 15 plastic greenhouses in the same district as Trial 2 with five replications of each treatment. Oriental melons were harvested seven times from 15 May to 3 June 2010. During the period for Trial 4, the temperature ranged from 6.5 to $28.5{ }^{\circ} \mathrm{C}$ with a cumulative precipitation of $285.3 \mathrm{~mm}$. Trial 5 was conducted from 28 Mar. to 31 Mar. 2010 in Fujian Province at the Baisha district of Fuzhou City (lat. $26.13^{\circ} \mathrm{N}$, long. $119.14^{\circ} \mathrm{E}$ ) with 10 replications for each treatment. Oriental melons were harvested seven times from 10 June to 2 July 2010. During the Trial 5 period, the temperature ranged from 10.5 to $37.5{ }^{\circ} \mathrm{C}$ with a cumulative precipitation of $325.3 \mathrm{~mm}$. Trial 6 was conducted from 18 Apr. to 24 Apr. 2010 in the same district as Trial 2 with 18 replications for each treatment. Oriental melons were harvested nine times from 2 July to 28 July 2010. During the period for Trial 6 , the temperature ranged from 15.6 to $38.8^{\circ} \mathrm{C}$ with a cumulative precipitation of $457.3 \mathrm{~mm}$. Trial 7 was conducted in nine plastic greenhouses from $18 \mathrm{Apr}$. to $20 \mathrm{Apr}$. 2011 in Fujian Province at the Geling district of Fuzhou City (lat. $25.48^{\circ} \mathrm{N}$, long. $118.44^{\circ} \mathrm{E}$ ) with three replications for each treatment. Oriental melons were harvested five times from 2 July to 16 July 2011 . During the period for Trial 7, the temperature ranged from 11.2 to $38.2{ }^{\circ} \mathrm{C}$ with a cumulative precipitation of $466.3 \mathrm{~mm}$. The temperature in the greenhouse was 3 to $4{ }^{\circ} \mathrm{C}$ higher than in the open field.

Fruits were harvested when the Oriental melon fruit pericarp color turned from green to white and when the dense tomentose faded. Then, 10 to 15 randomly selected plants from each treatment were used to calculate the fruit number, and 10 representative ripe fruit from each treatment were randomly selected for additional analyses. Fruit weight was measured using an electronic balance (HZ-HAW30C+; Hengzhizhan Electronic Co., Ltd., Fuzhou, China).

Plants affected by fusarium wilt were visually evaluated at each field location, and the pathogen was verified in the tissue by optical microscope observation (Booth, 1971). The number of wilted plants was recorded $60 \mathrm{~d}$ after transplanting Oriental melons in each field location. The disease incidence was calculated using the following formula: $100 \times$ (number of wilted plants per plot/total number of plants per plot). Oriental melon fruits were harvested in each plot, and the cumulative yields were calculated.

Carotenoid analysis. Evaluation of carotenoids was performed for Trial 1. Fruits were inspected carefully for bruising and compression damage and culled if it not in optimum condition. Fruits were washed thoroughly in cold running tap water and were then rinsed in deionized water. The stem and blossom portions $(\approx 1$ to $1.5 \mathrm{~cm})$ were removed, and each Oriental melon was sliced longitudinally. Seeds were removed, and the seed cavity was cleaned. Halves were cut into equatorial slices, from which all loose endocarp seed cavity tissue ( 1 to $2 \mathrm{~mm}$ thick) was removed. Processing was performed under strict sanitary conditions. Carotenoids were extracted using the method described by Bushway and Wilson (1982). Samples were prepared in triplicate, each from $10 \mathrm{~g}$ of randomized cubes from a minimum of five 
fruit per treatment. Chromatographic analysis was performed using an Agilent 1100 Series high-performance liquid chromatography Value System (Agilent Technologies, Waldbronn, Germany) equipped with four G1310A isocratic pumps with solvent cabinet, a G1323B local control module, a G1314A variable wavelength detector, a G1328A manual injector with a $20-\mu \mathrm{L}$ loop, and a G2220AA 2D-Value Solution ChemStation. The column was a $250 \mathrm{~mm} \times 4.6 \mathrm{~mm}$ i.d. Agilent $\mathrm{SB}-\mathrm{C}_{18}$ column with a $5-\mu \mathrm{m}$ particle size (Agilent Technologies) and was operated at $30{ }^{\circ} \mathrm{C}$. The mobile phase consisted of acetonitrile/dichloromethane/ethyl acetate 40 : $25: 35 \mathrm{v} / \mathrm{v} / \mathrm{v}$ (eluent A) and acetonitrile (eluent B) using a gradient program with the following percentages of eluents: $0 \%$ to $100 \%$ (start program), $100 \%$ to $0 \%$ (45 $\mathrm{min}$ ), and $0 \%$ to $100 \%$ (46 min). Total run time was $49 \mathrm{~min}$. The injection volume was $20 \mu \mathrm{L}$. Lutein, $\alpha$-carotene, $\beta$-carotene, and phytofluene were monitored at $\lambda=470 \mathrm{~nm}$; $\zeta$-carotene was monitored at $\lambda==360 \mathrm{~nm}$; and phytoene was monitored at $\lambda=280 \mathrm{~nm}$ at a flow rate of $1 \mathrm{~mL} \cdot \mathrm{min}^{-1}$. Furthermore, ultraviolet-765 spectra were recorded in the range of 225 to $600 \mathrm{~nm}$ at a spectral acquisition rate of 1.25 $\mathrm{scan} / \mathrm{s}$ (peak width $0.2 \mathrm{~min}$ ). Identification of carotenoids was based on the comparison of retention time and ultraviolet-765 spectra with the standard substances available (Sigma Aldrich, Shanghai, China). Quantitative analyses were performed using the external standard method, after construction of calibration graphs for $\beta$-carotene with coefficients of determination $\left(r^{2}\right)$ of 0.9980. Data were expressed as milligrams of $\beta$-carotene per kilogram of fresh fruit.

Statistical analyses. Analysis of variance for the experimental data were performed using SPSS for Windows (Version 16.0; SPSS, Inc., Chicago, IL). Mean comparisons were conducted using the least significant difference
(LSD) test $(P \leq 0.05$ or $P \leq 0.01)$. SES and the LSD results were recorded.

\section{Results and Discussion}

Field experiments. The results are presented in Table 1. Plants grafted on SYTZ and NZ1 exhibited decreased incidences of fusarium wilt disease and increased yields in field trials at Fuzhou City, Fujian Province, China. In six of the seven field trials, the grafted Oriental melons showed no incidence of fusarium wilt disease and had higher fruit yields compared with the nongrafted Oriental melons $(P<0.01)$. The disease was only recorded among grafted plants in Trial 3 at Hongwei (2009), where plants grafted on SYTZ and NZ1 exhibited $1.05 \%$ and $1.1 \%$ infection, respectively. In comparison, the incidence of disease of nongrafted Oriental melons ranged from $45.0 \%$ to $100.0 \%$ (Table 1). No significant differences were observed for fruit number of per plant or mean fruit weights among the three Liyu treatments (nongrafted and grafted onto Cucurbita rootstocks NZ1 and SYTZ) (Table 1). Liyu grafted onto SYTZ rootstock yielded 3.9 to $5.1 \mathrm{~kg} \cdot \mathrm{m}^{-2}$ fruit, whereas Liyu grafted onto NZ1 rootstock yielded 3.9 to $5.2 \mathrm{~kg} \cdot \mathrm{m}^{-2}$ fruit. There were no significant differences between the two treatments. However, the yield of nongrafted Oriental melons ranged from 0 to $1.8 \mathrm{~kg} \cdot \mathrm{m}^{-2}$ (Table 1 ).

In our study, we also found that Liyu Oriental melons were susceptible to all FOM races, whereas the two Cucurbita rootstocks exhibited high resistance to all FOM races in experiments in the greenhouse setting (data not shown). Therefore, grafting may represent an effective tool for controlling FOM and increasing yield in Oriental melon. Indeed, previous studies revealed that grafting of Oriental melon onto Cucurbita rootstocks SYTZ and NZ1 in the open field significantly reduces the incidence of fusarium wilt and increases the yield of fruit as compared with nongrafted Oriental melons (Wu et al., 2006, 2013; Wu and Zhao, 2007; Zhao et al., 2012a, 2012 b). Consistent with this, in our evaluation of the control of fusarium wilt and yield outputs of Liyu Oriental melon grafted onto SYTZ and NZ1, we found that Liyu Oriental melons grafted on SYTZ and NZ1 sharply reduced the incidence of fusarium wilt disease and increased Oriental melon yield compared with nongrafted Oriental melons. Even under cooler spring temperatures and high humidity (Trial 6, Hongwei) or greenhouse conditions (Trial 4, Hongwei; Trial 7, Geling), the two Cucurbita rootstocks effectively controlled fusarium wilt and increased yields (Table 1). The effects of these rootstocks can be noted by observation of some or all of the following processes: an increase of water and nutrient uptake resulting from the vigorous root system of the rootstock (Zhao et al., 2010), enhanced production of endogenous hormones (Qi et al., 2006b), enhanced scion vigor (Wu et al., 2006, 2013; Wu and Zhao, 2007; Zhao et al., 2010, 2012a, 2012b), and improved Oriental melon response to a variety of abiotic stresses, including moisture, nutrient, and temperature extremes (Wu et al., 2013). The joint action of some or all of these processes could explain the higher yield of Oriental melon plants, particularly on Cucurbita rootstocks resistant to FOM, as observed in the current study on SYTZ and NZ1.

The climatic conditions between the open field and greenhouse are different; the temperature and humidity in the greenhouse are usually higher than in the open field. These conditions (i.e., high temperature and humidity) are conducive to the development of fusarium wilt (Han et al., 2009). Therefore, the incidence of fusarium wilt in nongrafted Oriental melon fruit in the greenhouse was $100.0 \%$ with no yield (Table 1). However,

Table 1. Incidence of fusarium wilt and yield of nongrafted Oriental melon plants and Oriental melon plants grafted on Cucurbita rootstocks in different field trials.

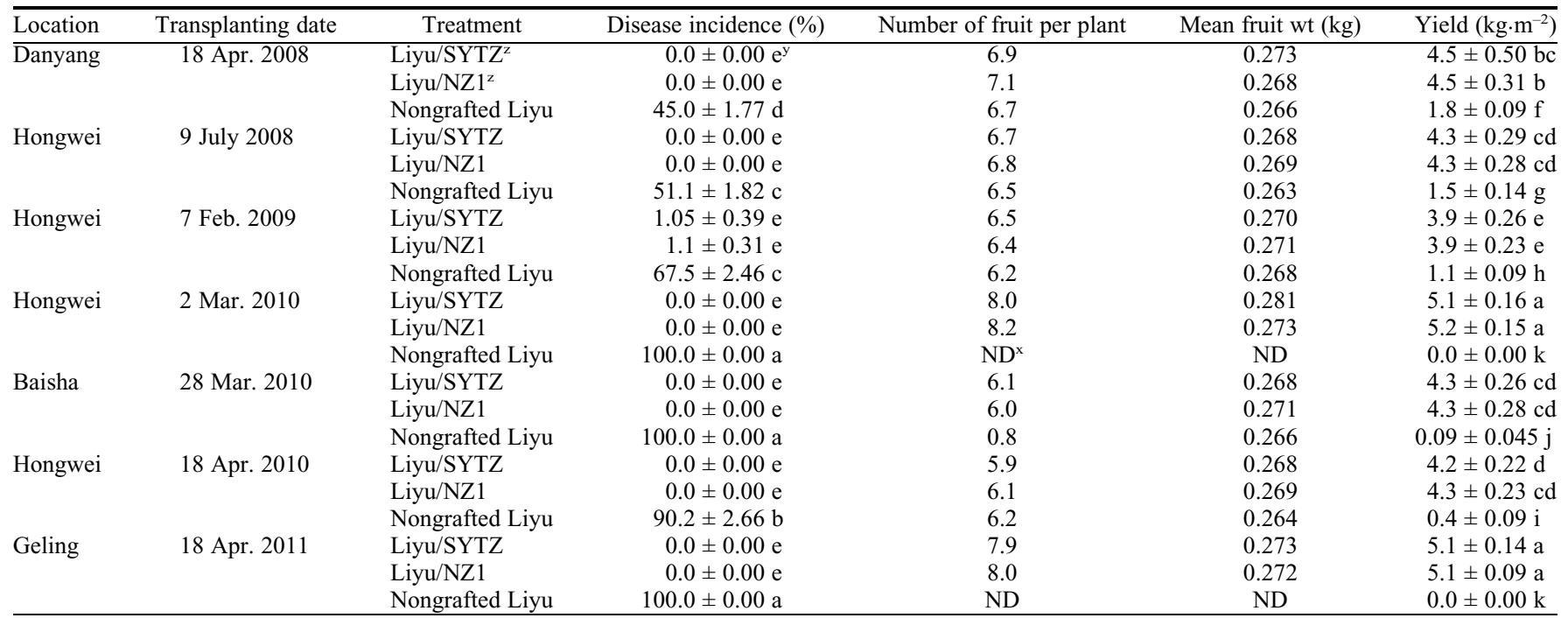

${ }^{{ }^{2} S Y T Z}$ and NZ1 = Shengyan Tianzhen and Nanzhen No. 1, respectively.

${ }^{y} \mathrm{Mean} \pm \mathrm{SD}$ followed by the same letters within a column were not significantly different as determined by the least significant difference test $(P \leq 0.05)$.

${ }^{\mathrm{x}} \mathrm{ND}=$ not detected 
Table 2. Content of carotenoids ( $\mu \mathrm{g} \cdot \mathrm{g}^{-1}$ of fresh weight) in nongrafted Oriental melon samples cv. Liyu and Oriental melon samples cv. Liyu grafted onto the Cucurbita rootstocks.

\begin{tabular}{|c|c|c|c|c|c|c|}
\hline Treatment & Lutein & $\zeta$-carotene & $\alpha$-carotene & Phytofluene & $\beta$-carotene & Phytoene \\
\hline$\overline{\text { Liyu }}$ & $0.0 \pm 0.00 \mathrm{~b}^{\mathrm{z}}$ & $10.7 \pm 2.03 \mathrm{~b}$ & $7.3 \pm 0.92 \mathrm{a}$ & $5.4 \pm 1.05 \mathrm{~b}$ & $14.9 \pm 1.55 b$ & $8.5 \pm 1.02 \mathrm{a}$ \\
\hline Liyu/SYTZ ${ }^{y}$ & $12.7 \pm 1.68 \mathrm{a}$ & $16.0 \pm 2.23 \mathrm{a}$ & $7.6 \pm 1.41 \mathrm{a}$ & $7.6 \pm 0.99 \mathrm{a}$ & $12.7 \pm 2.26 \mathrm{~b}$ & $7.9 \pm 0.85 \mathrm{a}$ \\
\hline Liyu/NZ1 ${ }^{\mathrm{y}}$ & $10.8 \pm 0.72 \mathrm{a}$ & $14.6 \pm 1.54 \mathrm{ab}$ & $8.7 \pm 0.64 \mathrm{a}$ & $6.4 \pm 0.54 \mathrm{ab}$ & $61.4 \pm 6.41 \mathrm{a}$ & $7.9 \pm 0.61 \mathrm{a}$ \\
\hline
\end{tabular}

${ }^{\mathrm{z}} \mathrm{SYTZ}$ and NZ1 = Shengyan Tianzhen and Nanzhen No. 1, respectively.

${ }^{\mathrm{y}}$ Mean \pm sD followed by the same letters within a column were not significantly different as determined by the least significant difference test $(P \leq 0.05)$.

extreme weather can also affect the yield and quality of Oriental melon fruits in the open field; consistent with this, we obtained higher yields of Oriental melon fruits in the greenhouse than in the open field (Table 1).

Carotenoid analysis. Analysis of carotenoid contents identified six compounds, i.e., $\alpha$-carotene, $\beta$-carotene, $\zeta$-carotene, lutein, phytoene, and phytofluene (Table 2). Liyu fruits from nongrafted plants were characterized by the predominance of $\beta$-carotene (14.9 $\mu \mathrm{g} \cdot \mathrm{g}^{-1}$ of fresh weight) and $\zeta$-carotene $(10.7$ $\mu \mathrm{g} \cdot \mathrm{g}^{-1}$ of fresh weight) and absence of lutein, the latter being detected only in fruit samples from Liyu grafted onto SYTZ and NZ1. In grafted samples, the lutein amounts of Liyu/ SYTZ and Liyu/NZ1 grafting combinations were 12.8 and $10.8 \mu \mathrm{g} \cdot \mathrm{g}^{-1}$ of fresh weight, respectively. The amounts of $\alpha$-carotene and phytoene in grafted samples were similar to those in nongrafted samples. In contrast, samples of Liyu grafted onto SYTZ and NZ1 exhibited different levels of $\zeta$-carotene and phytofluene than those in nongrafted samples. The amount of $\beta$-carotene in Liyu/ SYTZ samples was similar to that in nongrafted samples. However, samples of Liyu grafted onto NZ1 exhibited higher levels of $\beta$-carotene $(\approx 4$-fold more than that in nongrafted samples).

Thus, our data demonstrated that grafting affected the carotenoid composition of Oriental melon fruit. Interestingly, lutein was present in fruit samples from Liyu/SYTZ and Liyu/NZ1 grafting combinations, and $\beta$-carotene levels were increased in Liyu Oriental melon grafted onto NZ1 rootstock. Lutein and $\beta$-carotene are the main carotenoids in pumpkin (Azevedo-Meleiro and Rodriguez-Amaya, 2007) and were detected in Oriental melon fruit when C. maxima $\times$ C. moschata or C. moschata $\times$ C. moschata hybrids were used as rootstocks, indicating that metabolites associated with fruit nutritional quality translocated to the scion through the xylem. No reports in the literature have described the influence of grafting on the carotenoid composition of Oriental melon. However, Condurso et al. (2012) found that Proteo (C. melo L. var. reticulatus) grafted onto pumpkin hybrids rootstocks, Elsi, P360, RS841, and AS10 (C. maxima $\times$ C. moschata) improved the carotenoid profiles of fruit, resulting in increased levels of lutein, $\beta$-carotene, and $\alpha$-carotene in the Proteo/P360 grafting combination. In contrast, melon genotype rootstocks (i.e., Energia and Sting) resulted in decreased levels of $\beta$-carotene.

There are very few reports in the literature concerning the primary mechanism of the effects of grafting on carotenoid profiles.
Carotenogenesis in fruits and flowers is controlled by two regulatory mechanisms, namely regulation at the enzymatic level and transcriptional level of carotenoid biosynthesis genes. Even if significant progress has been made in the knowledge of carotenoid biosynthesis in plants, the mechanisms regulating this process are still poorly understood (Fraser and Bramley, 2004). Trudel and Ozbun (1971) found that the high level of carotenoid content in grafted vegetable crops is closely related to the high $\mathrm{K}$ concentration in the fruit because this cation is important for protein synthesis and the activity of acetic thiokinase. Acetic thiokinase is involved in the formation of acetyl CoA, a molecule implicated in biosynthesis of isopentenyl diphosphate, the first precursor of carotenoid content of fruits. Additionally, there is increased magnesium $(\mathrm{Mg})$ content in grafted fruits (Pulgar et al., 2000; Rouphael et al., 2008), and many higher plant enzymes involved in carotenoid biosynthesis require a divalent ion, typically $\mathrm{Mg}$ or manganese, for optimum activity (Fraser and Bramley, 2004). In the present study, we found that grafting with Cucurbita rootstocks increased carotenoid content in Liyu Oriental melons. Moreover, the SSC of ripe grafted fruit, a key fruit quality parameter, was lower in than that in nongrafted samples from the seven trials. Interestingly, the SSC in samples from the greenhouse was higher than that in samples from the open field (data not shown). However, despite these data, it is still not clear whether Cucurbita rootstocks contribute to the observed increase in fruit carotenoid content and whether the climatic conditions can influence fruit quality of Oriental melon. Further studies are needed to explore the potential mechanisms through which Cucurbita rootstocks affect the carotenoid profiles of Oriental melons.

\section{Conclusions}

SYTZ $(C$. maxima $\times C$. moschata $)$ and NZ1 (C. moschata $\times$ C. moschata) rootstocks were capable of significantly reducing the incidence of fusarium wilt and improving the productivity of the plants in different FOMinfested soil locations and during different seasons in Fuzhou. Additionally, SYTZ (C. maxima $\times$ C. moschata) and NZ1 (C. moschata $\times$ C. moschata) improved the carotenoid profiles of Oriental melons by inducing lutein expression and increasing levels of $\zeta$-carotene and phytofluene. In particular, $\beta$-carotene content was significantly increased in the Liyu/NZ1 combination. Thus, the results demonstrated the importance of screening for scion/rootstock combinations that result in high fruit quality (e.g., healthpromoting compounds) for development of successful grafting combinations and methods.

\section{Literature Cited}

Alves-Rodrigues, A. and A. Shao. 2004. The science behind lutein. Toxicol. Lett. 150:57-83.

Azevedo-Meleiro, C.H. and D.B. Rodriguez-Amaya. 2007. Qualitative and quantitative differences in carotenoid composition among Cucurbita moschata, Cucurbita maxima and Cucurbita pepo. J. Agr. Food Chem. 55:4027-4033.

Booth, C. 1971. The genus fusarium. Commonwealth Mycological Institute, Kew, Surrey, UK.

Bushway, R.J. and A.M. Wilson. 1982. Determination of $\alpha$ - and $\beta$-carotene in fruit and vegetables by HPLC. Can. Inst. Food Sci. Technol. J. 15:165-169.

Cao, J.R. 2011. Occurrence regularity and control strategy of Oriental melon fusarium wilt. Jilin Veg. 1:58

Chuwers, P., S. Barahart, P. Blanc, C.A. Brodkin, M. Cullen, T. Kelly, J. Keogh, G. Omean, J. Williams, and J.R. Balmes. 1997. The protective effect of beta-carotene and retinol on ventilatory function in an asbestos-exposed cohort. Amer. J. Respir. Crit. Care Med. 155:10661071.

Colla, G., Y. Rouphael, C. Leonardi, and Z. Bie. 2010. Role of grafting in vegetable crop grown under saline conditions. Sci. Hort. 127:147155.

Condurso, C., A. Verzera, G. Dima, G. Tripodi, P. Crinò, A. Paratore, and D. Romano. 2012. Effects of different rootstocks on aroma volatile compounds and carotenoid content of melon fruits. Sci. Hort. 148:9-16.

Crinò, P., C.L. Bianco, Y. Rouphael, G. Colla, F. Saccardo, and A. Paratore. 2007. Evaluation of rootstock resistance to fusarium wilt and gummy stem blight and effect on yield and quality of grafted 'Indorus' melon. HortScience 42:521-525.

Davis, A.R., P. Perkins-Veazie, Y. Sakata, S. LopezGalarza, J.V. Maroto, S.-G. Lee, Y.-C. Huh, Z. Sun, A. Miguel, S.R. King, R. Cohen, and J.-M. Lee. 2008. Cucurbit grafting. Crit. Rev. Plant Sci. 27:50-74.

Eliassen, A.H., S.J. Hendrickson, L.A. Brinton, J.E. Buring, H. Campos, Q. Dai, J.F. Dorgan, A.A. Franke, Y. Gao, M.T. Goodman, G. Hallmans, K.J. Helzlsouer, J. Hoffman-Bolton, K. Hultén, H.D. Sesso, A.L. Sowell, R.M. Tamimi, P. Toniolo, L.R. Wilkens, A. Winkvist, A. Zeleniuch-Jacquotte, W. Zheng, and S.E. Hankinson. 2012. Circulating carotenoids and risk of breast cancer: Pooled analysis of eight prospective studies. J. Natl. Cancer Inst. 104:1905-1915.

Fraser, P.D. and P.M. Bramley. 2004. The biosynthesis and nutritional uses of carotenoids. Prog. Lipid Res. 43:228-265.

Gaziano, J.M., J.E. Manson, L.G. Branch, G.A. Colditz, W.C. Willett, and J.E. Buring. 1995. A prospective study of consumption of carotenoids 
in fruits and vegetables and decreased cardiovascular mortality in the elderly. Ann. Epidemiol. 5:255-260.

Han, J.X., R.X. Hong, L. Zhou, Y. He, J.Y. Huang, S.H. Qin, W.X. Li, X.J. Fan, and T.Y. Li. 2009. Progresses in fusarium wilt study of watermelon, cucumber and melon. Chinese Cucurbits Veg. 1:32-35.

Huang, Y., Z.L. Bie, Q.S. Kong, J.J. Xie, and M.L. Fan. 2012. Research progress on grafting effect on fruit quality of watermelon and melon. China Veg. 1:10-18.

Johnson, E.J. 2002. The role of carotenoids in human health. Nutr. Clin. Care 5:56-65.

Khachik, F., G.R. Beecher, and M.B. Goli. 1991. Separation, identification, and quantification of carotenoids in fruits, vegetables and human plasma by high performance liquid chromatography. Pure Appl. Chem. 63:71-80.

Laur, L.M. and L. Tian. 2011. Provitamin A and vitamin C contents in selected Californiagrown cantaloupe and honeydew melons and imported melons. J. Food Compos. Anal. 24:194-201.

Lester, G.E. and F. Eischen. 1996. Beta-carotene content of postharvest orange-fleshed muskmelon fruit: Effect of cultivar, growing location and fruit size. Plant Foods Hum. Nutr. 49:191-197.

Li, W. 2013. Study on biological characters of different ploidy melon. Master diss., Northeast Agricultural University, Harbin, China.

Martyn, R.D. and M.E. Miller. 1996. Monosporascus root rot and vine decline: An emerging diseases of melons worldwide. Plant Dis. 80:716-725.
Pulgar, G., G. Villora, D.A. Moreno, and L. Romero. 2000. Improving the mineral nutrition in grafted watermelon plants: Nitrogen metabolism. Biol. Plant. 43:607-609.

Qi, H.Y., T.L. Li, Y.F. Liu, and D. Li. 2006 a. Effects of grafting on photosynthesis characteristics, yield and sugar content in melon. J. Shengyang Agric. Uni. 37:155-158.

Qi, H.Y., Y.F. Liu, D. Li, and T.L. Li. 2006 b. Effects of grafting on nutrient absorption, hormone content in xylem exudation and yield of melon (Cucumis melo L.). Plant Physiol. Commu. 42:199-202.

Rao, A.V. and L.G. Rao. 2007. Carotenoids and human health. Pharmacol. Res. 55:207-216.

Rouphael, Y., M. Cardarelli, G. Colla, and E. Rea. 2008. Yield, mineral composition, water relations, and water use efficiency of grafted mini-watermelon plants under deficit irrigation. HortScience 43:730-736.

Savvas, D., G. Colla, Y. Rouphael, and D. Schwarz. 2010. Amelioration of heavy metal and nutrient stress in fruit vegetables by grafting. Sci. Hort. 127:156-161.

Schwarz, D., Y. Rouphael, G. Colla, and J.H. Venema. 2010. Grafting as a tool to improve tolerance of vegetable to abiotic stresses: Thermal stress, water stress and organic pollutants. Sci. Hort. 127:162-171.

Slattery, M.L., J. Benson, K. Curtin, K.N. Ma, D. Schaeffer, and J.D. Potter. 2000. Carotenoids and colon cancer. Am. J. Clin. Nutr. 71:575-582.

Tian, Y.Y., L. Chen, Y. Xie, M.Y. Li, and W.L. Chen. 2011. Selection of antagonistic bacteria to melon fusarium wilt and their biocontrol effect in fields. Chinese Agr. Sci. Bull. 27:367371.

Trudel, M.J. and J.L. Ozbun. 1971. Influence of potassium on carotenoids content of tomato fruit. J. Amer. Soc. Hort. Sci. 96:763-765.

Wu, Y.F., Y. Chen, and Y.J. Zhao. 2006. Effect of pumpkin stocks on growth, development, yield and quality of grafted muskmelon. Fujian J. Agr. Sci. 21:354-359.

Wu, Y.F. and Y.J. Zhao. 2007. The physiological influence on grafted muskmelon of different pumpkin stocks. Chinese Agr. Sci. Bull. 23:253-256.

Wu, Y.F., Y.J. Zhao, S. Chen, and W.G. Zhang. 2013. Breeding of rootstock 'NANZHEN 1.' Fujian J. Agr. Sci. 28:680-684.

Yano, M., M. Kato, Y. Ikoma, A. Kawasaki, Y. Fukazawa, M. Sugiura, H. Matsumoto, Y. Oohara, A. Nagao, and K. Ogawa. 2005. Quantitation of carotenoids in raw and processed fruits in Japan. Food Sci. Technol. Res. $11: 13-18$

Zhao, Y.J., X.H. Zhang, H. Lin, and Y.Z. Chen. 2012a. Effect of white seed pumpkin stocks on growth, yield, and quality of grafted muskmelon. J. Agron. 2:40-43.

Zhao, Y.J., Y.F. Wu, X.H. Zhang, H. Lin, S. Chen, and W.G. Zhang. 2012b. Effects of two rootstocks on growth, yield, and quality of 'Xinshengyu' Oriental melon. Chinese Hort. Abstracts 1:5-6, 42.

Zhao, Y.J., X.H. Zhang, H. Lin, and Q. Lin. 2010. Effects of rootstocks on the nitrogen metabolism of muskmelon leaves. Chinese J. Tropical Crops 31:203-206. 